\title{
Targeting the Enteric Nervous System to Treat Metabolic Disorders? "Enterosynes" as Therapeutic Gut Factors
}

\author{
Claude Knauf ${ }^{a, b}$ Anne Abot ${ }^{a, b}$ Eve Wemelle ${ }^{a, b}$ Patrice D. Cani ${ }^{b, c}$ \\ a Institut National de la Santé et de la Recherche Médicale (INSERM), U1220, Université Paul Sabatier, UPS, Institut \\ de Recherche en Santé Digestive et Nutrition (IRSD), Toulouse, France; ${ }^{b}$ NeuroMicrobiota, European Associated \\ Laboratory (EAL) INSERM, Toulouse, France; ' UCLouvain, Université Catholique de Louvain, WELBIO - Walloon \\ Excellence in Life Sciences and BIOtechnology, Louvain Drug Research Institute, Metabolism and Nutrition Research \\ Group, Brussels, Belgium
}

\section{Keywords}

Enteric nervous system · Diabetes · Obesity

\begin{abstract}
The gut-brain axis is of crucial importance for controlling glucose homeostasis. Alteration of this axis promotes the type 2 diabetes (T2D) phenotype (hyperglycaemia, insulin resistance). Recently, a new concept has emerged to demonstrate the crucial role of the enteric nervous system in the control of glycaemia via the hypothalamus. In diabetic patients and mice, modification of enteric neurons activity in the proximal part of the intestine generates a duodenal hyper-contractility that generates an aberrant message from the gut to the brain. In turn, the hypothalamus sends an aberrant efferent message that provokes a state of insulin resistance, which is characteristic of a T2D state. Targeting the enteric nervous system of the duodenum is now recognized as an innovative strategy for treatment of diabetes. By acting in the intestine, bioactive gut molecules that we called "enterosynes" can modulate the function of a specific type of neurons of the enteric nervous system to decrease the contraction of intestinal smooth muscle cells. Here, we focus on the origins of enterosynes (hormones, neurotransmitters,
\end{abstract}

\section{KARGER}

(c) 2019 S. Karger AG, Basel

E-Mail karger@karger.com

www.karger.com/nen nutrients, microbiota, and immune factors), which could be considered therapeutic factors, and we describe their modes of action on enteric neurons. This unsuspected action of enterosynes is proposed for the treatment of T2D, but it could be applied for other therapeutic solutions that implicate communication between the gut and brain.

두 2019 S. Karger AG, Base

\section{Generalities about the Enteric Nervous System}

\section{Structural and Functional Organization of the Enteric}

Nervous System

The enteric nervous system (ENS), referred to as the "second brain," is an extensive network of different cell types located along the digestive tract (Fig. 1). Here, the ENS comprises three panenteric juxtapositioned networks - enteric neurons, enteric glial cells (EGCs), and interstitial cells of Cajal (ICCs) - organized in two main ganglionated plexuses: the submucosal plexus (also called Meissner's plexus) within the connective tissue of

All authors have contributed equally to this work.
Pr. Claude Knauf

INSERM U1220, IRSD, Paul Sabatier University, Purpan Hospital Bat B, CHU Purpan - Place du Docteur Baylac, CS 60039 FR-31024 Toulouse Cedex 3 (France)

E-Mail claude.knauf@inserm.fr 
Fig. 1. Communication between different cellular networks is important for ENS homeostasis. EEC, enteroendocrine cells; EGCs, enteric glial cells; ICCs, interstitial cells of Cajal; ACh, acetylcholine; NO, nitric oxide; IPAN, intrinsic primary afferent neurons.

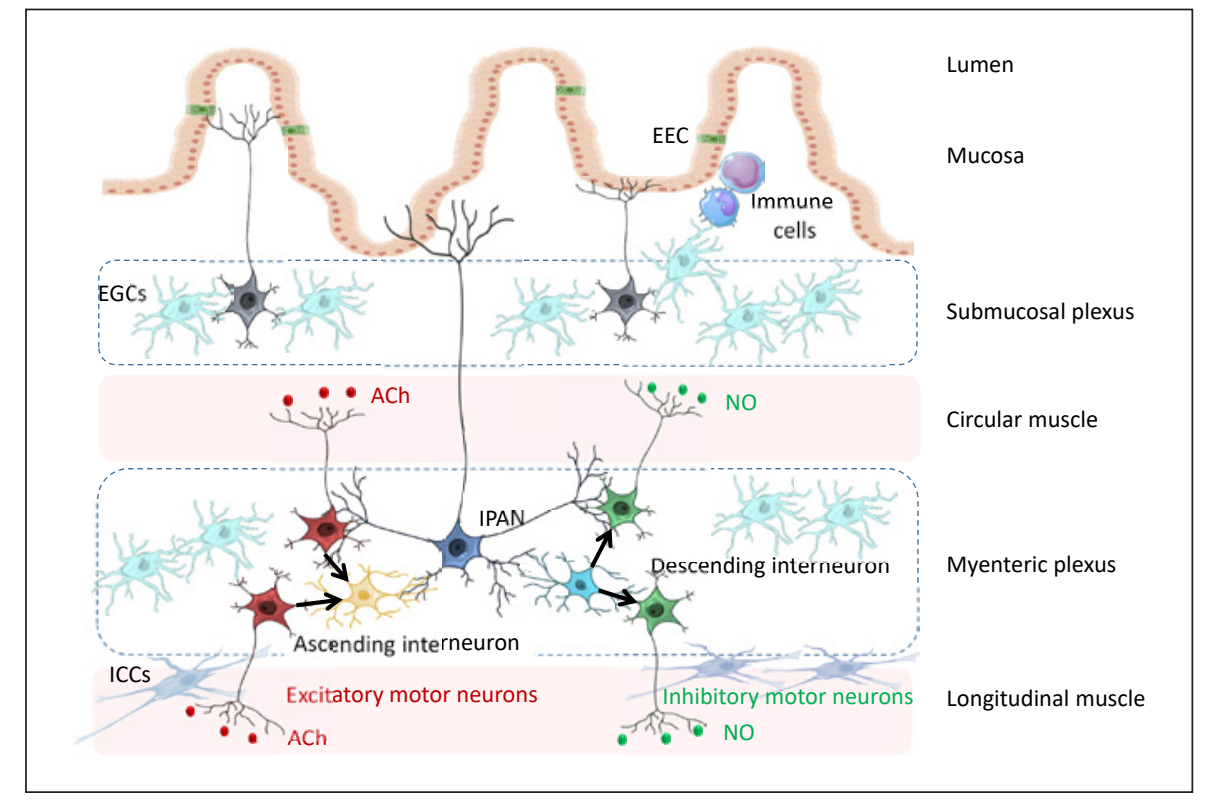

the submucosa of the intestinal wall and the myenteric plexus (also called Auerbach's plexus) located between the circular and longitudinal muscle layers [1]. The neurons, localized in the myenteric and submucosal plexuses, are organized into microcircuits and include intrinsic primary afferent neurons (IPANs) that can initiate reflexes, descending and ascending interneurons, and excitatory/inhibitory motor neurons that innervate the muscle [1]. Each functional type of enteric neurons is defined by a neurochemical code with extensive phenotypic diversity and is found in the central nervous system (CNS) [1]. The ENS is mostly composed of choline acetyl transferase and neuronal nitric oxide synthase (nNOS) neurons that respectively stimulate or inhibit directly intestinal smooth muscle cells or act on the hyperpolarization of ICCs [2].

Initially considered passive nutritional support cells for enteric neurons, EGCs regulate neuromediator expression, participate in neurotransmission and exert neuroprotective roles in the ENS. Enteric glia form a cellular and molecular integrator between enteric nerves, enteroendocrine cells, immune cells, and epithelial cells [3]. The ICCs are responsible for the generation of electrical impulses to smooth muscle cells, facilitating the slow-wave peristaltic movement of the stomach and intestines and are referred to as "pacemaker" cells [4].

To regulate gut functions and intestinal homeostasis, the ENS requires an accurate degree of regulation and coordination among these cell types.

\section{Physiological Role of the ENS}

The ENS provides local control of the gastrointestinal (GI) tract functions, such as secretion, barrier function and movement of fluid across the lining epithelium, regulation of local blood flow, interaction with the immune and endocrine systems of the gut, and intestinal motility [1].

The submucosal IPANs, in close proximity to the muscularis mucosae, intrinsic vasculature, and mucosa, regulate the secretion of hormones and neurotransmitters to maintain a regionally appropriate $\mathrm{pH}$ as well as tightly regulate the concentrations of electrolytes, enzymes, and mucus [1]. The epithelial cell facilitates the nutrient absorption and regulates the translocation of metabolites across the intestinal wall and maintains gut homeostasis $[5,6]$. EGCs play an essential role in maintaining the integrity of barrier functions. Previously, Bush et al. [7] have demonstrated that genetic ablation of enteric glia leads to increased oxidative stress, myenteric neuron degeneration, and intraluminal haemorrhage in mice.

Secretion and barrier functions are linked to gut motility: neuronal monitoring of the luminal content allows the transport of the chyme at a rate that allows each compartment to accomplish its task (e.g., digestion of food and absorption of nutrients) [5]. After food intake, mechanical and chemical stimuli induced by chyme activate first IPANs and mechanosensitive enteric neurons to regulate motility $[8,9]$. Motility reflexes, mainly regulated by myenteric neurons, are necessary for physiological digestion (propulsion by peristaltic waves and mixing the 
Fig. 2. Enterosynes from various origins can target enteric neurons and regulate their activity to restore a physiological gutbrain axis communication. ENS, enteric nervous system; GLP-1, glucagon-like peptide-1; TNF- $\alpha$, tumour necrosis factor alpha; IL- $1 \beta$, interleukin 1 beta; SCFA, shortchain fatty acids; GABA, gamma-aminobutyric acid; $\mathrm{NO}$, nitric oxide; $\mathrm{H}_{2} \mathrm{~S}$, hydrogen sulphide.

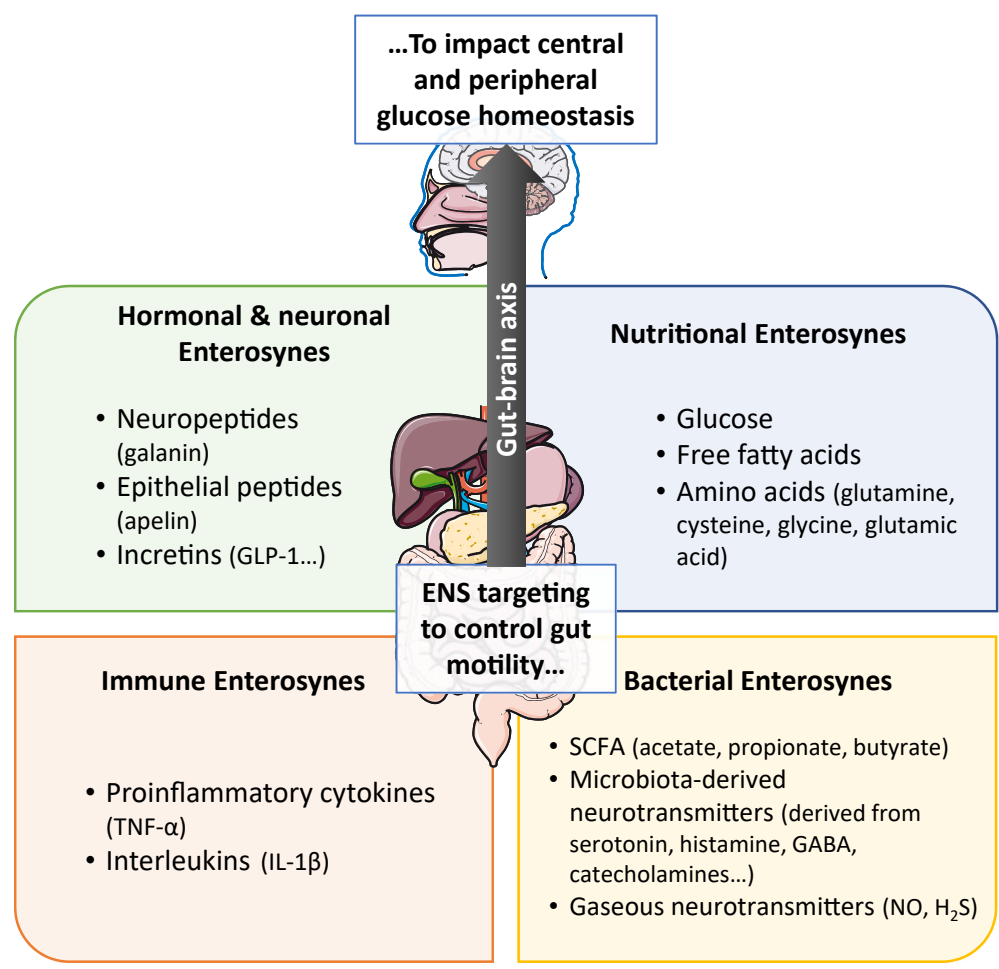

chyme by segmentation along the digestive tract) and favour nutrient absorption $[1,10]$.

The control of motility requires coordinated activation of neurons, EGCs and ICCs (for review: $[3,4]$ ). For instance, EGCs participate in intestinal motility and enteric neurotransmission by releasing $\mathrm{NO}$ or ATP, two major neurotransmitters involved in gut relaxation [11, 12], and, in ICC-lacking mice (W/Wv mutant), they present alteration of cholinergic and nitrergic neurotransmission in the small intestine [13].

Furthermore, the ENS is closely connected to the CNS, which also contributes to the regulation and coordination of GI functions. Actually, $80-85 \%$ of the sensory neurons, following either vagal or spinal routes, are afferent and project to the brain. The intestine wall is also supplemented with extrinsic efferent input from the CNS via autonomic (both sympathetic and parasympathetic) pathways. Therefore, the CNS can influence enteric behaviour to mediate the gut-brain communication and maintain gut homeostasis [14].

\section{Pathological Aspect of the ENS}

The alteration of ENS activity leads to enteric neuropathies, defined by a remodelled and dysfunctional ENS, that include the following: a reduced number and structure of intrinsic enteric neurons, intra-neuronal biochemical changes, a decrease in neurotransmitters release, alteration of immunomodulatory function of the EGCs, neuroinflammation, and altered gut-brain communication through spinal afferents and vagal terminals [15]. These changes cause altered GI motility, and secretory functions imply pathological complications.

Early in foetal ENS development, congenital alterations of migrative, proliferative, and maturation processes of enteric neural crest cells that populate the distal gut lead to Hirschsprung disease. This pathology is characterized by an abnormal glial phenotype, severe motility disorders, and lethal pseudo-obstruction due to enteric ganglia deficiencies in patients and experimental models [16-18].

During life, ENS deficiencies are correlated with an increased number of CNS disorders from neurodevelopmental (autism disorders) to neurodegenerative (Parkinson and Alzheimer diseases). In some of these pathologies, dysfunctional GI symptoms might occur even before CNS manifestations become evident and include alteration of neurotransmission, release of pro-inflammatory cytokines from EGCs, Lewy's bodies, or A $\beta$ plaque deposits on enteric neurons (for review: [19-21]). 
Furthermore, environmental conditions have a significant negative impact on the function of the ENS such as an inflammatory state and/or oxidative stress. Numerous pieces of evidence have shown that diabetes alters the microenvironment within the ENS. This deleterious effect could have various origins that include gluco- and lipotoxicity, oxidative stress, inflammation, reduction of neurotrophic factors, and alteration of gut microbiota $[15$, 22]. The resulted selective loss of nitrergic neurons (which control gut relaxation) is associated with intestinal hypercontractility [22-25]. Nutritionally, experimental models have shown that a high-fat diet induces functional and structural damage in myenteric neurons and ICCs that disrupt neural circuits, causing symptoms of dysmotility and correlating with neuropathy in the myenteric plexus of obese mice with symptoms of type 2 diabetes from the duodenum to the colon [26, 27]. In previous studies, we have demonstrated that alterations of nutrients and/or hormone sensing in the intestine are associated with aberrant hypothalamic responses that could lead to pathological states, including type 2 diabetes [24, 25].

In fact, physiopathological mechanisms of GI enteric neuropathies are complex and multifactorial and can affect both afferent and efferent connections between ENS and CNS, leading to the emergence of pathologies. Thus, gutbrain communication is essential for health maintenance.

\section{ENS and "Enterosynes"}

Numerous factors can modulate the activity of the ENS. Because most have an intestinal origin and due to their growing physiological impact, we decided to call them "enterosynes" (Fig. 2). To introduce the general concept, targeting the ENS is now considered a (relatively) recent approach to treat metabolic disorders and associated pathologies such as type 2 diabetes, obesity, and overfeeding. The chemical nature of enterosynes is extremely variable (e.g., bioactive peptides/lipids, sugar, gaseous factors), as well as their origins (i.e., host, gut microbiota, and food). Here, we will focus our attention on the most described enterosynes with an impact on the control of metabolism in the whole body.

\section{Neuronal and Hormonal Enterosynes}

Numerous receptors for hormones and/or neurotransmitters are expressed at the level of the membrane of enteric neurons. The activity of ENS neurons could be under the influence of various molecular actors from the sympathetic and parasympathetic system, enteric neu- rons themselves, and gut hormones. As we define "enterosynes" as "local intestinal" factors, we will here focus only on gut neurotransmitters and gut hormones.

Regarding gut neurotransmitters implicated in the control of glucose homeostasis, galanin is one of the most important factors that controls the ENS. Galanin is located on ENS neurons that also express other neurotransmitters such as substance $\mathrm{P}$ and corticotropin-releasing factor. Immunoreactivity for the 3 galanin receptors (GalR1, GalR2, and GalR3) has been demonstrated in the myenteric neurons of various species [28]. Galanin can decrease cholinergic transmission [29] and stimulate nitrergic transmission [25] of the ENS to decrease intestinal contractions. Recently, we have discovered that oral treatment of galanin is associated with improved glucose tolerance in diabetic mice [25]. In fact, this treatment decreases the duodenal hyper-contractility [25] observed during type 2 diabetes in humans and mice [30]. In this model, the apparent reduction in duodenal mechanical contraction is then sensed by the hypothalamus, which, in turn, sends a message in the periphery to increase glucose uptake. This observation was one of the first to present this new concept that targeting the "ENS-duodenal contraction" couple could be considered a novel target to treat type 2 diabetes [31].

Another gut factor implicated in the control of ENS activity is apelin. Apelin is released in the intestinal lumen by enterocytes in response to glucose [32]. Thus, apelin can be reached via transcytosis in the ENS and stimulate NO release from nNOS neurons that express the apelin receptor APJ [24]. Similar to galanin, the decrease in duodenal contraction observed in response to apelin improves the metabolic status of diabetic mice via the gutbrain axis. The study of the effects of apelin in the gut is only at the beginning and its role in the control of gut physiology starts to be documented (for review: [33]). To complete this idea, the link between apelin and CCK release is well documented because its receptors are also expressed on CCK-releasing neurons [34].

Another example of enterosynes is the hormone glucagon-like peptide-1 (GLP-1). GLP-1 is released by Lcells in response to various nutrients such as lipids and glucose [35] but also through different metabolites produced by the gut microbiota [36-38]. The GLP-1 receptor (GLP-1R) is expressed on enteric neurons [39], and its stimulation decreases cholinergic and stimulates nitrergic neurotransmissions [40]. This effect of GLP-1 on ENS is associated with a relaxant action in the antrum [41] and colon [42]. A part of the action of GLP-1 on enteric neurons could be responsible for the well-known effect of this peptide on the reduction of food intake [43]. 


\section{Nutritional Enterosynes}

Different nutrients such as glucose, free fatty acids, and amino acids modulate the activity of ENS neurons. As evidence, an unbalanced and hyper-caloric diet may participate in the alteration of ENS, leading to hyperglycaemia. The link between ENS and glucose was discovered by Paton and Zar in 1968 [44], who discovered that the output of acetylcholine from the Auerbach's plexus is decreased in absence of glucose. Whether the "glucose sensor" of enteric neurons is of crucial importance for the control of whole-body metabolism is poorly studied (for review: [45]). To summarize, evidence has suggested that glucose sensing in the enteric neurons can be indirect via GLP-1, which acts on its enteric receptor or directly by an action of glucose on a specific transporter [45]. By performing immunohistochemistry studies, Diez-Sampedro et al. [46] showed that SGLT3 is expressed on cholinergic enteric neurons in the myenteric and submucosal plexi that potentially gives glucose the possibility to modulate directly the release of acetylcholine. During type 2 diabetes, enteric glucose sensing is profoundly altered, leading to the disturbance of the gut-brain axis, which results in an insulin-resistance state [47-49]. However, the electrophysiological modifications of glucose detection by enteric neurons during diabetes remain to be determined.

Among all amino acids, glutamine is one of the most documented amino acids for its action on ENS. In the gut, glutamine is considered a precursor for the synthesis of glutathione, one of the major endogenous cellular antioxidants. As explained above, the ENS is altered during type 2 diabetes, and glutamine supplementation to diabetic rats prevents the neuronal loss in the myenteric plexus [50]. This neuroprotective action of glutamine on ENS is exerted on various types of neurons that include nNOS, vasoactive intestinal polypeptide, and calcitonin gene-related peptide neurons [51]. Glutathione formed by the addition of cysteine, glycine, and glutamic acid seems to be more efficient than glutamine alone [52]. The neuroprotective effect of glutamine on nNOS neurons could decrease the duodenal hyper-contractility observed in diabetic mice [5, $24,25]$ and then could exert an anti-diabetic effect. At this time, almost nothing is known regarding this potential new mode of action on ENS neurons, but the anti-diabetic impact of glutamine is well documented. However, the group of Fiona Gribble has clearly shown that oral glutamine could improve glycaemia in diabetic patients [53-55] via a direct action on GLP-1-synthesized cells $[56,57]$.

The potential direct effect of free fatty acids on enteric neurons seems only to require the free fatty acid receptor 3 (FFAR3 or GPR41) expressed on ENS neurons [58]. This receptor binds to specific ligands such as the short-chain fatty acids (SCFAs) acetate, propionate, or butyrate. Most FFAR3-expressing neurons in the ENS are cholinergic neurons, and activation of FFAR3 leads to the inhibition of these neurons [59]. In this context, Kaji et al. [60] have demonstrated that activation of FFAR3 suppresses neurogenic activity of the intestine by suppressing nicotinic acetylcholine receptor-mediated neural pathways. This last result suggests that FFAR3 activation could be considered a new target to treat colon hyper-contractility observed during diarrhoea. This concept adapted to the duodenal hyper-contractility to prevent hyperglycaemia remains to be determined. In addition, as gut microbiota is considered the major source of SCFAs in the whole body [61], the impact of the microbial SCFAs will be described below.

\section{Microbial Enterosynes}

The human gut microbiota is now perceived as a key partner, contributing to the production of numerous factors that regulate host metabolism. Although the human GI tract can digest and absorb the nutrients present in our diet, a certain amount of nutrients escapes the digestive process and is then handled by the gut microbes.

Among the undigested nutrients, some carbohydrates will be fermented by the gut microbiota and are then transformed into SCFAs (for review: [62]). Interestingly, it was demonstrated that SCFAs activate specifically FFAR3 (as described earlier) but also FFAR2 (also known as GPR43), which are expressed on enteroendocrine Lcells, thereby promoting the secretion of different gut peptides involved in glucose and energy metabolism, such as GLP-1 and PYY [58]. Therefore, depending on the source of fermentable carbohydrates $[63,64]$, the gut microbiota will control the production of those intestinal peptides and eventually regulate appetite, body weight, and fat mass gain but also insulin sensitivity (for review: [36]).

Gut microbes harbour various enzymatic machinery, contributing to the production of SCFAs, but many other compounds are also made and can reach not only the intestinal epithelial cells but also different organs located at a distance from the gut, such as the liver, brain, and adipose tissue [65-67]. In fact, the gut microbiota is also synthesizing different neurotransmitters. The effects of these different molecules are various, and, although produced at the level of the intestinal tract, their effects can be observed at the local but also at the peripheral level. Actually, those neurotransmitters not only act at the local level, thereby controlling the gut physiology (i.e., motility, intestinal hormones production) but also at a distance, such as on the brain (i.e., appetite, cognition, and behav- 
iour). Among the different microbiota-derived neurotransmitters, we can cite those derived from amino acids, such as serotonin, histamine, and gamma-aminobutyricacid, butalso catecholamines, such as norepinephrine and dopamine [68]. The gut bacteria residing in the human gut can also release several types of gases composed of the following chemical elements: nitrogen, oxygen, hydrogen, methane, and carbon monoxide $[69,70]$. Consequently, gut microbes synthesize the so-called gaseous neurotransmitters nitric oxide (NO) and hydrogen sulphide $\left(\mathrm{H}_{2} \mathrm{~S}\right)$ [71]. Along these lines, it is important to note that a novel concept linking microbial molecules and glucose metabolism has recently emerged and demonstrates that the inhibition of proximal gut motility improves hyperglycaemia observed during type 2 diabetes [24, 25]. More precisely, given that $\mathrm{NO}$ and $\mathrm{H}_{2} \mathrm{~S}$ exert tonic inhibition of smooth muscle cells, it is speculated that, by impacting on gut muscle relaxation, gut bacteria directly participate in the control of glycaemia $[24,25,72]$.

In conclusion, the gut microbiota composition is now considered an important contributor that regulates health. However, the causality between gut bacteria and diseases remains debated and requires further investigations.

\section{Immune Enterosynes}

Intestinal inflammation is a well-described process that occurs during metabolic disorders. Recently, we published a review summarizing the link between immune cells and the ENS [73]. Essentially, enteric neurons express various receptors for immune factors such as TNF- $\alpha$ [74]. Regarding its origin, TNF- $\alpha$ could be released by immune cells [73] or by enteric neurons themselves [75]. TNF- $\alpha$ can potentiate the response to nicotinic receptor stimulation in cultured rat myenteric neurons [76], which could provoke intestinal hyper-contractility. In addition, this increase of pro-inflammatory cytokines could have a direct impact on enteric glucose sensing. In fact, Duparc et al. [49] have demonstrated that jejunal IL-1 $\beta$ expression is increased in diabetic mice associated with an alteration of gut glucose sensing-to-brain axis. Nonetheless, a controversy exists in the literature because cytokines (such as TNF- $\alpha$ and IL-1 $\beta$ ) can exert beneficial neurotrophic effects [77].

\section{Conclusion}

Targeting the ENS to treat metabolic disorders and associated phenotypes such as insulin resistance, hyperglycaemia, or overfeeding is now considered an original ap- proach. Although this concept is well described for gut peptides (i.e., apelin, galanin, and GLP-1), the development of different innovative molecules such as specific bioactive lipids and bacterial factors will offer new opportunities to improve the efficacy of novel anti-diabetic drugs. As the link between ENS and the brain is of crucial importance in this physiological system, the concept of "targeting the ENS" can be applied for multiple pathologies. This can also be the case for neurological disorders, such as Parkinson's disease. Nevertheless, the concept can be extended to all physiological functions that are under the control of the brain.

\section{Statement of Ethics}

The authors have no ethical conflicts to disclose.

\section{Disclosure Statement}

P.D.C. and C.K. are co-founders of Enterosys S.A. (Labège, France). A.A. is employed by Enterosys S.A. (Labège, France). P.D.C. is a co-founder of A-Mansia Biotech S.A. (Belgium) and owner of several patents concerning the use of microbiota and health.

\section{Funding Sources}

This work is supported by the Agence Nationale de la Recherche (ANR) grant (ANR-18-CE14-0007-01). P.D.C. is a senior research associate at FRS-FNRS (Fonds de la Recherche Scientifique) and recipient of grants from FNRS (FRFS-WELBIO-CR-2017-C02, "The Excellence Of Science: EOS 30770923") and the Funds Baillet Latour (Grant for Medical Research 2015).

\section{Author Contributions}

P.D.C., A.A., E.W., and C.K. wrote the manuscript. All authors contributed equally to this work.
References
1 Furness JB. The enteric nervous system and neurogastroenterology. Nat Rev Gastroenterol Hepatol. 2012 Mar;9(5):286-94.

2 Gallego D, Mañé N, Gil V, Martínez-Cutillas M, Jiménez M. Mechanisms responsible for neuromuscular relaxation in the gastrointestinal tract. Rev Esp Enferm Dig. 2016 Nov; 108(11):721-31.

3 Sharkey KA. Emerging roles for enteric glia in gastrointestinal disorders. J Clin Invest. 2015 Mar;125(3):918-25. 
4 Mostafa RM, Moustafa YM, Hamdy H. Interstitial cells of Cajal, the Maestro in health and disease. World J Gastroenterol. 2010 Jul; 16(26):3239-48.

5 Abot A, Cani PD, Knauf C. Impact of Intestinal Peptides on the Enteric Nervous System: Novel Approaches to Control Glucose Metabolism and Food Intake. Front Endocrinol (Lausanne). 2018 Jun;9:328.

6 Turner JR. Intestinal mucosal barrier function in health and disease. Nat Rev Immunol. 2009 Nov;9(11):799-809.

7 Bush TG, Savidge TC, Freeman TC, Cox HJ, Campbell EA, Mucke L, et al. Fulminant jejunoileitis following ablation of enteric glia in adult transgenic mice. Cell. 1998 Apr;93(2):189-201.

8 Furness JB, Kunze WA, Bertrand PP, Clerc N, Bornstein JC. Intrinsic primary afferent neurons of the intestine. Prog Neurobiol. 1998 Jan;54(1):1-18.

9 Mazzuoli G, Schemann M. Multifunctional rapidly adapting mechanosensitive enteric neurons (RAMEN) in the myenteric plexus of the guinea pig ileum. J Physiol. 2009 Oct; 587(Pt 19):4681-94.

10 Sababi M, Bengtsson UH. Enhanced intestinal motility influences absorption in anaesthetized rat. Acta Physiol Scand. 2001 Jun; 172(2):115-22.

11 McClain J, Grubisic V, Fried D, Gomez-Suarez RA, Leinninger GM, Sevigny J, Parpura V, Gulbransen BD: Ca2+ responses in enteric glia are mediated by connexin- 43 hemichannels and modulate colonic transit in mice. Gastroenterology 2014;146:497-507 e491.

12 MacEachern SJ, Patel BA, McKay DM, Sharkey KA. Nitric oxide regulation of colonic epithelial ion transport: a novel role for enteric glia in the myenteric plexus. J Physiol. 2011 Jul;589(Pt 13):3333-48.

13 Ward SM, McLaren GJ, Sanders KM. Interstitial cells of Cajal in the deep muscular plexus mediate enteric motor neurotransmission in the mouse small intestine. J Physiol. 2006 May;573(Pt 1):147-59.

14 Furness JB, Callaghan BP, Rivera LR, Cho HJ. The enteric nervous system and gastrointestinal innervation: integrated local and central control. Adv Exp Med Biol. 2014;817:39-71.

15 Meldgaard T, Olesen SS, Farmer AD, Krogh K, Wendel AA, Brock B, et al. Diabetic Enteropathy: From Molecule to Mechanism-Based Treatment. J Diabetes Res. 2018 Sep;2018:3827301.

16 Badizadegan K, Thomas AR, Nagy N, Ndishabandi D, Miller SA, Alessandrini A, et al. Presence of intramucosal neuroglial cells in normal and aganglionic human colon. Am J Physiol Gastrointest Liver Physiol. 2014 Nov; 307(10):G1002-12.

17 Tam PK. Hirschsprung's disease: A bridge for science and surgery. J Pediatr Surg. 2016 Jan; 51(1):18-22.

18 Bondurand N, Southard-Smith EM. Mouse models of Hirschsprung disease and other developmental disorders of the enteric nervous system: old and new players. Dev Biol. 2016 Sep;417(2):139-57.
19 Rao M, Gershon MD. The bowel and beyond: the enteric nervous system in neurological disorders. Nat Rev Gastroenterol Hepatol. 2016 Sep;13(9):517-28.

20 Klingelhoefer L, Reichmann H. Pathogenesis of Parkinson disease - the gut-brain axis and environmental factors. Nat Rev Neurol. 2015 Nov;11(11):625-36.

21 Neunlist M, Rolli-Derkinderen M, Latorre R, Van Landeghem L, Coron E, Derkinderen P, et al. Enteric glial cells: recent developments and future directions. Gastroenterology. 2014 Dec;147(6):1230-7.

22 Yarandi SS, Srinivasan S. Diabetic gastrointestinal motility disorders and the role of enteric nervous system: current status and future directions. Neurogastroenterol Motil. 2014 May;26(5):611-24.

23 Chandrasekharan B, Anitha M, Blatt R, Shahnavaz N, Kooby D, Staley C, Mwangi S, Jones DP, Sitaraman SV, Srinivasan S: Colonic motor dysfunction in human diabetes is associated with enteric neuronal loss and increased oxidative stress. Neurogastroenterology and motility : the official journal of the European Gastrointestinal Motility Society 2011;23: 131-138, e126. https://doi.org/ 10.1111/j.1365-2982.2010.01611.x.

24 Fournel A, Drougard A, Duparc T, Marlin A, Brierley SM, Castro J, et al. Apelin targets gut contraction to control glucose metabolism via the brain. Gut. 2017 Feb;66(2):258-69.

25 Abot A, Lucas A, Bautzova T, Bessac A, Fournel A, Le-Gonidec S, et al. Galanin enhances systemic glucose metabolism through enteric Nitric Oxide Synthase-expressed neurons. Mol Metab. 2018 Apr;10:100-8.

26 Stenkamp-Strahm CM, Nyavor YE, Kappmeyer AJ, Horton S, Gericke M, Balemba OB. Prolonged high fat diet ingestion, obesity, and type 2 diabetes symptoms correlate with phenotypic plasticity in myenteric neurons and nerve damage in the mouse duodenum. Cell Tissue Res. 2015 Aug;361(2):411-26.

27 Choi KM, Gibbons SJ, Nguyen TV, Stoltz GJ, Lurken MS, Ordog T, Szurszewski JH, Farrugia G: Heme oxygenase-1 protects interstitial cells of Cajal from oxidative stress and reverses diabetic gastroparesis. Gastroenterology 2008; 135:2055-2064, 2064 e2051-2052. https://doi.org/10.1053/j.gastro.2008.09.003.

28 Arciszewski MB, Barabasz S, Całka J. Immunohistochemical localization of galanin receptors (GAL-R1, GAL-R2, and GAL-R3) on myenteric neurons from the sheep and dog stomach. Ann Anat. 2008;190(4):360-7.

29 Sternini C, Anselmi L, Guerrini S, Cervio E, Pham T, Balestra B, et al. Role of galanin receptor 1 in peristaltic activity in the guinea pig ileum. Neuroscience. 2004;125(1):103-12.

30 Chandrasekharan B, Srinivasan S. Diabetes and the enteric nervous system. Neurogastroenterol Motil. 2007 Dec;19(12):951-60.

31 Weber C. Neurogastroenterology: improving glucose tolerance via the gut-brain axis. Nat Rev Gastroenterol Hepatol. 2015.
32 Dray C, Sakar Y, Vinel C, Daviaud D, Masri B, Garrigues L, et al. The intestinal glucose-apelin cycle controls carbohydrate absorption in mice. Gastroenterology. 2013 Apr;144(4):771-80.

33 Huang Z, Luo X, Liu M, Chen L. Function and regulation of apelin/APJ system in digestive physiology and pathology. J Cell Physiol. 2018.

34 Bülbül M, Sinen O, Bayramoğlu O, Akkoyunlu G. Acute restraint stress induces cholecystokinin release via enteric apelin. Neuropeptides. 2019 Feb;73:71-7.

35 Burcelin R, Cani PD, Knauf C. Glucagon-like peptide-1 and energy homeostasis. J Nutr. 2007 Nov; 137(11 Suppl):2534S-8S.

36 Rastelli M, Knauf C, Cani PD. Gut Microbes and Health: A Focus on the Mechanisms Linking Microbes, Obesity, and Related Disorders. Obesity (Silver Spring). 2018 May; 26(5):792-800.

37 Claus SP. Will Gut Microbiota Help Design the Next Generation of GLP-1-Based Therapies for Type 2 Diabetes? Cell Metab. 2017 Jul;26(1):6-7.

38 Everard A, Cani PD. Gut microbiota and GLP-1. Rev Endocr Metab Disord. 2014 Sep; 15(3):189-96.

39 Richards P, Parker HE, Adriaenssens AE, Hodgson JM, Cork SC, Trapp S, et al. Identification and characterization of GLP-1 receptor-expressing cells using a new transgenic mouse model. Diabetes. 2014 Apr;63(4): 1224-33.

40 Amato A, Cinci L, Rotondo A, Serio R, Faussone-Pellegrini MS, Vannucchi MG, et al. Peripheral motor action of glucagon-like peptide-1 through enteric neuronal receptors. Neurogastroenterol Motil. 2010 Jun;22(6): 664-e203.

41 Rotondo A, Amato A, Lentini L, Baldassano $S$, Mulè F. Glucagon-like peptide-1 relaxes gastric antrum through nitric oxide in mice. Peptides. 2011 Jan;32(1):60-4.

42 Amato A, Baldassano S, Liotta R, Serio R, Mulè F. Exogenous glucagon-like peptide 1 reduces contractions in human colon circular muscle. J Endocrinol. 2014 Mar;221(1):2937.

43 Washington MC, Raboin SJ, Thompson W, Larsen CJ, Sayegh AI. Exenatide reduces food intake and activates the enteric nervous system of the gastrointestinal tract and the dorsal vagal complex of the hindbrain in the rat by a GLP-1 receptor. Brain Res. 2010 Jul;1344: 124-33.

44 Paton WD, Zar MA. The origin of acetylcholine released from guinea-pig intestine and longitudinal muscle strips. J Physiol. 1968 Jan; 194(1):13-33.

45 Fournel A, Marlin A, Abot A, Pasquio C, Cirillo C, Cani PD, et al. Glucosensing in the gastrointestinal tract: impact on glucose metabolism. Am J Physiol Gastrointest Liver Physiol. 2016 May;310(9):G645-58.

46 Diez-Sampedro A, Hirayama BA, Osswald C, Gorboulev V, Baumgarten K, Volk C, et al. A glucose sensor hiding in a family of transporters. Proc Natl Acad Sci USA. 2003 Sep; 100(20):11753-8. 
47 Knauf C, Cani PD, Kim DH, Iglesias MA, Chabo C, Waget A, et al. Role of central nervous system glucagon-like Peptide-1 receptors in enteric glucose sensing. Diabetes. 2008 Oct;57(10):2603-12.

48 Knauf C, Cani PD, Perrin C, Iglesias MA, Maury JF, Bernard E, et al. Brain glucagonlike peptide-1 increases insulin secretion and muscle insulin resistance to favor hepatic glycogen storage. J Clin Invest. 2005 Dec; 115(12):3554-63

49 Duparc T, Naslain D, Colom A, Muccioli GG, Massaly N, Delzenne NM, et al. Jejunum inflammation in obese and diabetic mice impairs enteric glucose detection and modifies nitric oxide release in the hypothalamus. Antioxid Redox Signal. 2011 Feb;14(3):415-23.

50 Pereira RV, Tronchini EA, Tashima CM, Alves EP, Lima MM, Zanoni JN. L-glutamine supplementation prevents myenteric neuron loss and has gliatrophic effects in the ileum of diabetic rats. Dig Dis Sci. 2011 Dec;56(12):3507-16.

51 Pereira RV, Linden DR, Miranda-Neto $\mathrm{MH}$, Zanoni JN. Differential effects in CGRPergic, nitrergic, and VIPergic myenteric innervation in diabetic rats supplemented with $2 \% \mathrm{~L}$ glutamine. An Acad Bras Cienc. 2016;88 Suppl 1:609-22.

52 Hermes-Uliana C, Panizzon CP, Trevizan AR, Sehaber CC, Ramalho FV, Martins HA, et al. Is L-glutathione more effective than Lglutamine in preventing enteric diabetic neuropathy? Dig Dis Sci. 2014 May;59(5):937-48.

53 Greenfield JR, Farooqi IS, Keogh JM, Henning E, Habib AM, Blackwood A, et al. Oral glutamine increases circulating glucagon-like peptide 1, glucagon, and insulin concentrations in lean, obese, and type 2 diabetic subjects. Am J Clin Nutr. 2009 Jan;89(1):106-13.

54 Meek CL, Reimann F, Park AJ, Gribble FM. Can encapsulated glutamine increase GLP-1 secretion, improve glucose tolerance, and reduce meal size in healthy volunteers? A randomised, placebo-controlled, cross-over trial. Lancet. 2015 Feb;385 Suppl 1:S68.

55 Samocha-Bonet D, Wong O, Synnott EL, Piyaratna N, Douglas A, Gribble FM, et al. Glutamine reduces postprandial glycemia and augments the glucagon-like peptide- 1 response in type 2 diabetes patients. J Nutr. 2011 Jul;141(7):1233-8.

56 Reimann F, Williams L, da Silva Xavier G, Rutter GA, Gribble FM. Glutamine potently stimulates glucagon-like peptide-1 secretion from GLUTag cells. Diabetologia. 2004 Sep; 47(9):1592-601.
57 Tolhurst G, Zheng Y, Parker HE, Habib AM, Reimann F, Gribble FM. Glutamine triggers and potentiates glucagon-like peptide- 1 secretion by raising cytosolic Ca2+ and cAMP. Endocrinology. 2011 Feb;152(2):405-13.

58 Nøhr MK, Pedersen MH, Gille A, Egerod KL, Engelstoft MS, Husted AS, et al. GPR41/ FFAR3 and GPR43/FFAR2 as cosensors for short-chain fatty acids in enteroendocrine cells vs FFAR3 in enteric neurons and FFAR2 in enteric leukocytes. Endocrinology. 2013 Oct;154(10):3552-64.

59 Kaji I, Akiba Y, Konno K, Watanabe M, Kimura S, Iwanaga T, et al. Neural FFA3 activation inversely regulates anion secretion evoked by nicotinic ACh receptor activation in rat proximal colon. J Physiol. 2016 Jun; 594(12):3339-52

60 Kaji I, Akiba Y, Furuyama T, Adelson DW, Iwamoto K, Watanabe M, et al. Free fatty acid receptor 3 activation suppresses neurogenic motility in rat proximal colon. Neurogastroenterol Motil. 2018 Jan;30(1):30.

61 Inoue D, Tsujimoto G, Kimura I. Regulation of Energy Homeostasis by GPR41. Front Endocrinol (Lausanne). 2014 May;5:81.

62 Louis P, Flint HJ. Formation of propionate and butyrate by the human colonic microbiota. Environ Microbiol. 2017 Jan;19(1):29-41.

63 Brooks L, Viardot A, Tsakmaki A, Stolarczyk E, Howard JK, Cani PD, et al. Fermentable carbohydrate stimulates FFAR2-dependent colonic PYY cell expansion to increase satiety. Mol Metab. 2016 Nov;6(1):48-60.

64 Koh A, De Vadder F, Kovatcheva-Datchary P, Bäckhed F. From Dietary Fiber to Host Physiology: Short-Chain Fatty Acids as Key Bacterial Metabolites. Cell. 2016 Jun;165(6):133245.

65 Frost G, Sleeth ML, Sahuri-Arisoylu M, Lizarbe B, Cerdan S, Brody L, et al. The shortchain fatty acid acetate reduces appetite via a central homeostatic mechanism. Nat Commun. 2014 Apr;5(1):3611

66 Canfora EE, Jocken JW, Blaak EE. Shortchain fatty acids in control of body weight and insulin sensitivity. Nat Rev Endocrinol. 2015 Oct;11(10):577-91.

67 Cani P.D. VHM, Lefort C., Depommier C., Rastelli M., Everard A.: Microbial regulation of organismal energy homeostasis. Nature metabolism 2019;1:34-46.
68 Asano Y, Hiramoto T, Nishino R, Aiba Y, Kimura T, Yoshihara K, et al. Critical role of gut microbiota in the production of biologically active, free catecholamines in the gut lumen of mice. Am J Physiol Gastrointest Liver Physiol. 2012 Dec;303(11):G1288-95.

69 Scaldaferri F, Nardone O, Lopetuso LR, Petito $\mathrm{V}$, Bibbò $\mathrm{S}$, Laterza $\mathrm{L}$, et al. Intestinal gas production and gastrointestinal symptoms: from pathogenesis to clinical implication. Eur Rev Med Pharmacol Sci. 2013;17 Suppl 2: 2-10.

70 Pimentel M, Mathur R, Chang C. Gas and the microbiome. Curr Gastroenterol Rep. 2013 Dec;15(12):356.

71 Luhachack L, Nudler E. Bacterial gasotransmitters: an innate defense against antibiotics. Curr Opin Microbiol. 2014 Oct;21:13-7.

72 Jimenez M, Gil V, Martinez-Cutillas M, Mañé N, Gallego D. Hydrogen sulphide as a signalling molecule regulating physiopathological processes in gastrointestinal motility. $\mathrm{Br}$ J Pharmacol. 2017 Sep;174(17):2805-17.

73 Bessac A, Cani PD, Meunier E, Dietrich G, Knauf C. Inflammation and Gut-Brain Axis During Type 2 Diabetes: Focus on the Crosstalk Between Intestinal Immune Cells and Enteric Nervous System. Front Neurosci. 2018 Oct; $12: 725$.

74 Chandrasekharan B, Jeppsson S, Pienkowski S, Belsham DD, Sitaraman SV, Merlin D, et al. Tumor necrosis factor-neuropeptide $Y$ cross talk regulates inflammation, epithelial barrier functions, and colonic motility. Inflamm Bowel Dis. 2013 Nov; 19(12):2535-46.

75 Coquenlorge S, Duchalais E, Chevalier J, Cossais F, Rolli-Derkinderen M, Neunlist M. Modulation of lipopolysaccharide-induced neuronal response by activation of the enteric nervous system. J Neuroinflammation. 2014 Dec;11(1):202.

76 Rehn M, Hübschle T, Diener M. TNF-alpha hyperpolarizes membrane potential and potentiates the response to nicotinic receptor stimulation in cultured rat myenteric neurones. Acta Physiol Scand. 2004 May;181(1): $13-22$.

77 Gougeon PY, Lourenssen S, Han TY, Nair DG, Ropeleski MJ, Blennerhassett MG. The pro-inflammatory cytokines IL- $1 \beta$ and TNF $\alpha$ are neurotrophic for enteric neurons. J Neurosci. 2013 Feb;33(8):3339-51. 